\title{
Tackling Child Undernutrition in India: Governance Challenges Need More Attention
}

\author{
Jaydeep Biswas and Jaya Singh Verma
}

\begin{abstract}
This article puts a governance lens on India's current approach to tackling undernutrition through DFID's governance framework of state capability, accountability and responsiveness. State capability is analysed in terms of strength of political leadership to tackle undernutrition and to mobilise cross government actions. Accountability for results is assessed in the Integrated Child Development Scheme (ICDS) - India's foremost programme for children under six years of age with nutrition and health as one of the programme components. Finally, state responsiveness is assessed especially with respect to the Right-toFood (RTF) campaign that has taken a legal route to advocacy by successfully petitioning the Supreme Court (SC) that has directed the Government of India (Gol) to improve the functioning of ICDS - with a special focus on the disadvantaged sections of the population.
\end{abstract}

Children - too lean and short for their age, and with oversized heads from which vivid eyes shine ... (Arvind Adiga in The White Tiger - winner of the 2008 Booker Prize)

\author{
1 Introduction \\ India has the highest level of child \\ undernutrition in the world, along with \\ Bangladesh and Nepal. Half of India's 150 \\ million children under six years of age are \\ underweight, and progress has particularly \\ slowed down in recent years. Between the \\ National Family Health Survey (NFHS-3 in 2005) \\ and the NFHS-2 (1998) there has been hardly \\ any progress - the proportion of underweight \\ children under three years of age came down by \\ a mere 1 per cent - from 47 per cent to 46 per \\ cent (GoI 2007d). Worse still, child \\ undernutrition in two of the bigger states, Bihar \\ and Madhya Pradesh (MP) has increased \\ between the NFHS-2 and NFHS-3.
}

This is a poor record by any standards. But when it happens in a country that is blazing the economic growth trail - with at least an average rate of over 6 per cent - in the last 15 years something is seriously wrong. Achieving Inclusive
Growth is the focus of India's Eleventh Five-Year Plan - and without making progress on undernutrition, it cannot be achieved.

Why is India's track record in tackling child undernutrition so poor? Is it primarily because the political priority to tackle child nutrition has remained weak? Is it principally because nutrition has remained the orphan child of policymaking - relegated to the exclusive domain of the 34-year-old Integrated Child Development Scheme (ICDS: http://wcd.nic.in) ${ }^{1}$ - that aims to achieve too many things with too few resources and without much accountability for results? Although successful in many ways, the ICDS scheme has failed to make a significant dent in reducing the proportion of underweight children, which continues to be one of the highest in the world (GoI 2007e). Is it because the public service delivery mechanism to tackle health and nutrition has not changed even with significantly higher financial allocations? ${ }^{2}$

It is now widely accepted that for any public programme to deliver well for the poor and socially excluded, governance plays a central role. Governance is the exercise of political 
Table 1 Malnutrition statistics by caste/tribe, India - NFHS-3

\begin{tabular}{lllll}
\hline & $\begin{array}{l}\text { Scheduled } \\
\text { caste }\end{array}$ & $\begin{array}{l}\text { Scheduled } \\
\text { tribe }\end{array}$ & $\begin{array}{l}\text { Other backward } \\
\text { castes }\end{array}$ & Other \\
\hline Children under 3 years who are stunted (\%) & 44.1 & 44.3 & 39.2 & 31.1 \\
Children under 3 years who are wasted (\%) & 20.5 & 25.7 & 18.9 & 16.4 \\
Children under 3 years who are underweight (\%) & 52.2 & 56.7 & 46.4 & 37.3
\end{tabular}

authority and the use of institutional resources to manage society's problems and affairs (World Bank 1991). Since governance is at the heart of setting out public policy priorities, resource allocation and utilisation of public resources - it plays a crucial role in producing socially desirable outcomes. 'Disadvantaged' groups, especially the scheduled castes, the scheduled tribes and other minorities, must feel they have an equal stake and should perceive an adequate flow of benefits to ensure the legitimacy of the state (GoI 2007b).

This article puts a governance lens on India's current approach to tackling undernutrition through the Department for International Development's (DFID) framework of state capability, accountability and responsiveness. We analyse state capability in terms of strength of political leadership to tackle undernutrition and to mobilise cross government actions which are essential to tackle child undernutrition. We then assess the accountability for results in ICDS India's foremost programme for children under six years of age, tasked to provide pre-school education to children and to break the vicious cycle of malnutrition, morbidity, reduced learning capacity and mortality. ICDS is assessed on infrastructure, staff vacancies, supplementary nutrition, planning and monitoring systems and gender and nutrition and health education (NHE). Finally, we analyse state responsiveness, particularly with respect to the Right-to-Food (RTF) campaign that has taken a legal route to advocacy by successfully petitioning the Supreme Court (SC) to direct the GoI to improve the functioning of ICDS - with a special focus on the disadvantaged sections of the population.

\section{Child undernutrition in India: benefits of economic growth bypass the socially excluded} India's children are in a state of humanitarian emergency, with about 75 million of them being undernourished. Eight states in India bear a lion's share of the burden. ${ }^{3}$ For this article, we use data mostly from four states - Bihar, Madhya Pradesh, Orissa and West Bengal. These four states cover 25 per cent of India's population (Census of India 2001).

The picture is exacerbated by significant inequalities across states and socioeconomic groups - girls, rural areas, the poorest and scheduled tribes and castes are the worst affected - and these inequalities appear to be increasing (World Bank 2005). A child born in the poorest household is three times as likely to die before she reaches her fifth birthday compared with a child born in the richest household (UNICEF/KPMG 2008).

Children from the marginalised groups such as scheduled tribes/scheduled castes (ST/SC) households are significantly worse off (refer to Table 1). Undernutrition rates are higher among young girls ${ }^{4}$; and for SC and ST women, these rates are alarming - 56 per cent and 65 per cent, respectively. Young and undernourished mothers especially from ST/SC groups are likely to give birth to underweight babies that have serious intergenerational equity implications.

It is now well understood that more than 15 years of rapid economic growth has not helped much in tackling undernutrition, especially for the socially excluded groups. The immediate story is about poor resource allocation to ICDS. Even as late as in 2005 - after ten continuous years of high economic growth - the total budgetary allocation for ICDS (national and state government combined) was Rs. 45 billion. Counting the 150 million children under six years of age that ICDS targets, this means government allocates Rs. 300/child annually less than Rs. 1/day. However, resources for ICDS have been increased by $30-40$ per cent in the last $4-5$ years. This has been possible because of very high revenue growth in recent years in India. 


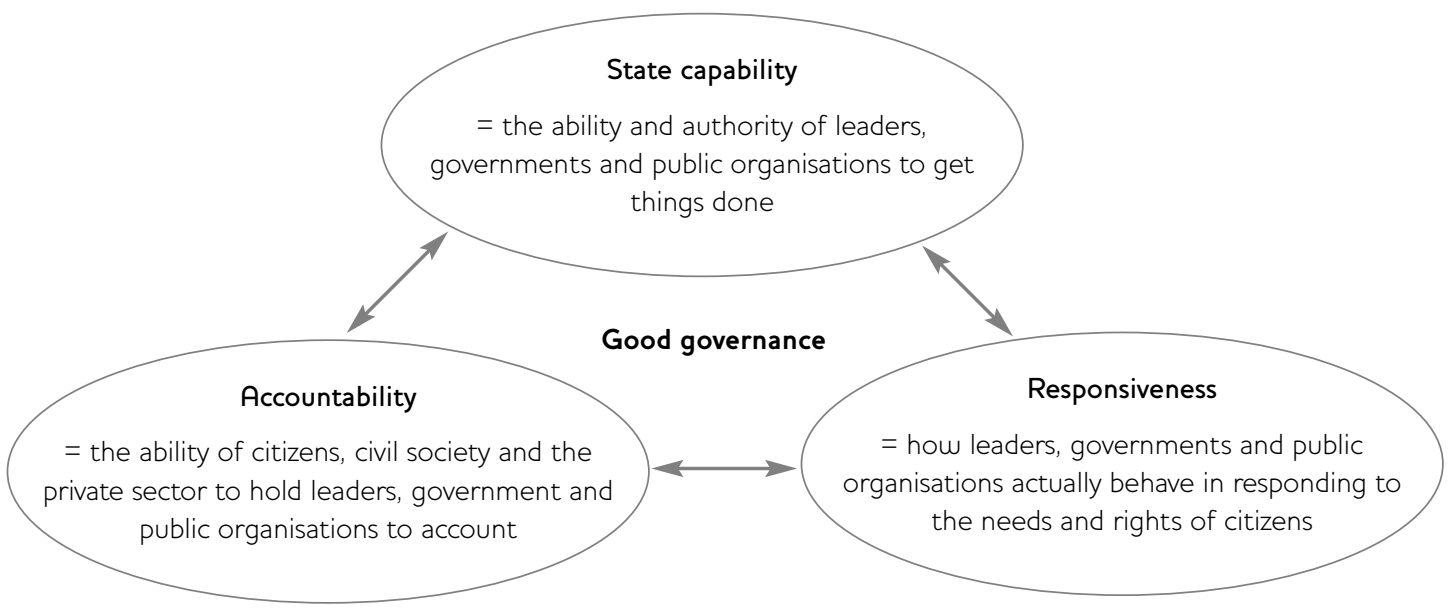

The impact of such higher resource allocation to ICDS is yet to be ascertained. We argue in this article that unless governance challenges pay more attention to tackling undernutrition, such higher resource allocations will not necessarily result in more desirable nutritional outcomes.

\section{The governance framework}

Improving governance is seen as central to improving public service delivery. It is critical for addressing corruption, human rights abuse, social exclusion and gender inequality, and for reducing the risk of violent conflict and instability (DFID 2007).

For the purpose of this article, we use DFID's governance framework (Figure 1) that uses three parameters of capability, accountability and responsiveness.

Since this framework has been operationalised through Country Governance Analysis (CGA) in several DFID supported countries, we are confident about the practical usefulness of this three-dimensional framework (DFID 2008).

\subsection{State capability \\ Political leadership}

State capability is a function of political leadership. The political leadership to tackle undernutrition in India has not been strong enough. Only 3 per cent of questions raised in Parliament, during the last four years relate to children (Working Group on Children Under Six
2007). About 1 per cent of the Union Budget is spent on children under six years of age (UNICEF 2007). Media scan reveals very few concrete policy pronouncements from the political leadership on undernutrition. '... Health and well being of children is really not a priority with political parties' (Ramachandran 2005). Due to the lack of high level political leadership, 25 years after the introduction of ICDS, the Supreme Court of India had to intervene and provide several directives since 2001 to provide improved coverage and quality of nutrition and health services especially to disadvantaged groups.

However, since the publication of the NFHS-3 findings in 2007 - and in the backdrop of India's growing stature as an economic power - there seems to be a spurt in political pressure on the government to tackle undernutrition on an urgent basis. This pressure to act comes from the Planning Commission within the government and from the civil society advocacy movement, the media and multilateral agencies from outside. The Prime Minister (PM) forcefully articulated the need to improve nutrition statistics in his Independence Day speech on 15 August 2008 'The problem of malnutrition is a curse that we must remove' - and in the week before announced the establishment of the PM's National Council on India's Nutrition Challenges. The PM's Council has the potential to place nutrition at the heart of government priority with support coming from the Planning Commission 
and the Women and Child Development (WCD) Ministry. Also, in recent months there has been greater priority accorded to designing an Integrated Child Protection Scheme (with nutrition as one of the focus areas) and then there is the ICDS IV that takes a more targeted approach to addressing child undernutrition for children under two years of age. The PM's Council is yet to make any major policy impact and with national elections intervening - things will be on hold for some time. Hopefully, once the new government is formed, the PM's Council will be retained and activated to breathe new life into the government's child undernutrition agenda. Such an apex body should drive the agenda nationally so that state governments respond to a coherent national plan.

Some lessons may be learnt from the recent actions taken on the Climate Change agenda another difficult cross-government issue - in which India's National Action Plan on Climate Change has resulted in the setting up of eight inter-sectoral Missions to get the entire government to respond coherently. When compared with the advocacy blitz on climate change in terms of media space and the support provided by the international development agencies, undernutrition pales in comparison. This points to a need for the stepping up of advocacy efforts by each of the actors and also calls for a greater joining up of Indian civil society forces and international agencies to advocate for a stronger policy response on tackling undernutrition.

\section{Cross-government action}

India's undernutrition problem is deeply rooted in vast poverty. About 456 million Indians live on less than the international poverty line set at US $\$ 1.25$ a day (World Bank 2009) and 900 million live on less than US $\$ 2$ a day (DFID 2008), and in international comparison, India is facing alarming hunger - ranked 66th among 88 countries on the global hunger index. There is a high level of basic hunger in poorer areas and among the socially excluded groups. Sanitation conditions are very poor (with coverage not more than $30-40$ per cent across the country). In rural India, 84 per cent of the population defecate in the open and 17 per cent in urban areas do so (UNICEF 2009).

Until recently, food insecurity was viewed as the primary cause of malnutrition in India. However, research shows that exposure to repeated infections, inadequate utilisation of health services, poor sanitation, inappropriate child feeding/caring practices, especially in the first two years of life, and the low status of women are among the key factors contributing to high malnutrition in India (GoI 2007c). Half of Indian children are underweight and live in hungry households; they are not fully immunised, are exposed to high levels of unsanitary conditions and fall into a cycle of high morbidity (and mortality), undernutrition and infections. The inter-sectoral nature of the problem requires coordinated and effective cross-government action.

But state capability to organise cross-government actions to tackle undernutrition is weak. A number of cross-government strategies at the state level on undernutrition is not operationalised effectively. The state level committees on ICDS have not been effective. This is not surprising, since overall political priority is weak. The Chief Ministers or other senior Ministers who play lead roles in crossgovernment coordination on priority matters for, e.g. investment promotion and industrialisation, do not get much involved in ICDS matters. As a result, undernutrition remains relegated only to ICDS - a scheme that sits within WCD - and operates vertically downwards from the national government to the state/district level with few interlinkages with health, local government, education, water and sanitation and public distribution sectors.

\subsection{Accountability for results - ICDS}

Stronger accountability in public service delivery should lead to better outcomes. In this section, we assess accountability for results in ICDS on infrastructure, personnel, supplementary nutrition programme, gender, nutrition and health education and planning and monitoring. It is the only programme addressing the care, education, health and nutrition concerns of children under six. ICDS5 addresses a range of children's needs under one umbrella through a network of more than 1 million Anganwadi centres (AWC or centres) ${ }^{6}$ at the village/urban slum level.

\section{Infrastructure}

ICDS envisages Anganwadi centres to be safe, hygienic and attractive places for children to grow, play and learn. 
Table 2 AWC infrastructure

\begin{tabular}{|c|c|c|c|c|}
\hline & Bihar & Madhya Pradesh & Orissa & West Bengal \\
\hline $\begin{array}{l}\text { AWCs without proper } \\
\text { building/space }\end{array}$ & $\begin{array}{l}43 \% \text { running } \\
\text { in huts }\end{array}$ & $74 \%$ & $\begin{array}{l}53 \% \text { in non- } \\
\text { departmental } \\
\text { buildings }\end{array}$ & $\begin{array}{l}10 \% \text { running in the open without } \\
\text { shelter and } 83 \% \text { in various other places } \\
\text { such as clubs, attached verandahs, } \\
\text { temporary sheds }\end{array}$ \\
\hline Without drinking water & $97 \%$ & $55 \%$ & $64 \%$ & $62 \%$ \\
\hline Without toilets & $98 \%$ & $45 \%$ & $99 \%$ & $94 \%$ \\
\hline
\end{tabular}

Source Comptroller and Auditor General (CAG) Reports (2005-07).

Table 2 reveals that a high percentage of AWCs do not have a proper building and many are held in the open. Two-thirds of ICDS buildings operate from rented premises which invariably are in the upper caste locality thus favouring their children and neglecting lower caste children (Saxena and Ravi 2005, NAC papers). With almost no drinking water and toilets and poor infrastructure in the AWCs, the plight of small children can be well imagined. The Women and Child Development (WCD) Ministry reports that a survey by National Council of Applied Economic Research (NCAER) ${ }^{7}$ covering a number of states found 45 per cent of AWCis do not have toilet facilities and only 39 per cent reported having a hand pump. Various field visits corroborate this story.

Simply put, the main centre of programme delivery of ICDS is crumbling and contributes to the low uptake of ICDS. The percentage of children receiving any benefits from the AWC is 32.9 per cent (NFHS 3). The government has been active in increasing the number of AWCs over the years; but so far, not enough urgency is visible in getting the infrastructure of AWCs up to the required norms and to make them operationally effective and attractive. Evidence on the quality of infrastructure of the new ICDS centres is not yet available in any systematic form.

\section{Personnel}

ICDS is a human resource intensive programme with 35-50 per cent of its budget spent on personnel. It employs about 2 million anganwadi workers (AWW) and helpers at the front-line who deliver the ICDS package of services. They are supported by supervisors (supervising 20-30 centres in each sector). The first line of management support is provided by Child Development Project Officers (CDPOs) posted at the block level (covering a population of 100,000-200,000).

Table 3 reveals high levels of vacancies in CDPOs and supervisors who are responsible for providing operational support to the AWW. In MP, performance review by CAG notes 'The work of assisting and guiding the AWWs, mobilising and motivating beneficiaries, coordination between AWWs and CDPOs was adversely affected as 549 posts (about 25 per cent) of Supervisors were vacant'. Similar observations have been made by CAG for the three other states. However, things are changing in Bihar, which shows renewed political priority for

Table 3 Vacancies in operational staff

\begin{tabular}{lllll}
\hline & Bihar & Madhya Pradesh & Orissa & West Bengal \\
\hline CDPOs & $66 \%$ & $50-75 \%$ & $30 \%$ & $26 \%$ \\
Supervisors & $86 \%$ & $25 \%$ & $39 \%$ & $35 \%$ \\
AWWs & $25 \%$ & $\mathrm{~N} / \mathrm{A}$ & $10 \%$ & $5 \%$ \\
Statistical assistant & $83 \%$ & $50-83 \%$ & $\mathrm{~N} / \mathrm{A}$ & \\
\hline
\end{tabular}

Source Compiled from CAG reports/MPR. 
At the front-line, ICDS is delivered by an Anganwadi woman worker and her assistant who draw honoraria ranging from Rs. 1,000 to Rs. 2,000. CAG test checked reports suggest AWWs are often assigned some additional duties not related to the ICDS scheme such as general census, literacy programme, identification of disabled children, survey of tuberculosis, leprosy, AIDS and malaria patients, revision of electoral rolls and photoidentity cards, survey works of PHCs and formation of self-help groups, etc. And then there are her main duties which is the heavy workload of record keeping in at least ten formats, arranging and managing supplementary nutrition, making home visits, holding womens' group meetings, giving health counselling, organising cooking classes for women and teaching about 30-60 pre-school children!

The question needs to be asked - how much can an AWW deliver even if she did her best? Because of vacancies in higher levels and lack of supportive supervision and the multiplicity of tasks that she is required to perform, the AWW is the link in the delivery chain where the heaviest responsibility is concentrated. It is as if the entire nation's responsibility to combat undernutrition has been delegated to this 'honorary worker'.

recruitment of front-line public servants including GDPOS, etc. West Bengal has also made attempts to recruit in recent times.

We could not ascertain all the India figures on vacancy positions because it is not available in any easy form. However, based on the data available from the four states it seems this is a big problem that affects many other states. Since these vacancies are proportionally more in the 'underserved and hard-to-reach areas', it damages service delivery where it is acutely required. ICDS IV too does not seem to be designed to pay adequate attention to higher level personnel issues beyond that of the AWWs.

Many State governments are mired in legal cases related to recruitment, transfers and postings of staff that delay deployment of the right people where needed. Another stumbling block is the lack of an integrated personnel information system and almost non-existent personnel/ human resource sections within the department, which deters any kind of proper planning. Most ICDS departments are serviced by a manually operated database of staff. As a result, ad hoc measures are taken regarding deployment of staff which usually means 'easy' posts are filled up and posts in more remote/difficult areas are not. Without staff in the posts, supervision and performance management becomes meaningless. To help solve this problem, governments need to re-look at the whole range of personnel policy covering recruitment, training, postings, promotions and transfers on an urgent basis and in an integrated manner. The adopted policies should also be made transparent for them to be fairly enforced. Without sorting out the higher level personnel issues, delivery at the front-line will be hard to improve and AWWs will continue to be burdened with a heavy workload and without adequate support (Box 1).

\section{Supplementary Nutrition Programme (SNP) - procurement and financial management}

Supplementary nutrition is one of the most important interventions of ICDS. As per the Supreme Court Orders of 2004, all AWCs are required to provide 300 days of supplementary nutrition to all children, adolescent girls, pregnant and lactating mothers. State governments are responsible for the supply of nutritious food for which the GoI provides 50 per cent reimbursement. A national level evaluation by the National Institute of Public Cooperation and Child Development (NIPCCD) in 2006 reveals that only 45 per cent of registered children receive supplementary nutrition (GoI 2007a).

Table 4 reveals that feeding interruptions at the AWC level is serious - ranging from a few days to few months. No AWC could provide more than 225 days - far short of the mandatory 300 days of feeding during the tenth five-year plan (2002-2007) in Bihar. NFHS-3 found that supplementary nutrition coverage of under-three year-old children across the country was only 26 per cent. Field reports/visits reveal feeding interruption is more in the remote and hard to reach, tribal blocks. 
Table 4 No. of days of feeding provided by AWCs

\begin{tabular}{lllll}
\hline $\begin{array}{l}\text { No of days of } \\
\text { supplementary } \\
\text { nutrition provided }\end{array}$ & $\begin{array}{l}\text { Bihar (100 AWCs } \\
\text { test checked } \\
\text { sample) }\end{array}$ & Madhya Pradesh & Orissa & $\begin{array}{l}\text { West Bengal (test check } \\
\text { sample of } \mathbf{4 4 2} \text { AWCs) }\end{array}$ \\
\hline $0-100$ & $46 \%$ & Food interruptions ranged & $4 \%$ & $69 \%$ AWCs provided \\
$100-200$ & $47 \%$ & from several days to several & $36 \%$ & between 26-150 days \\
$200-225$ & $7 \%$ & $\begin{array}{l}\text { months in Sehore, Mandla, } \\
\text { Vidisha and Damoh districts. }\end{array}$ & $\begin{array}{l}60 \%(200-300 \\
\text { days) }\end{array}$ & $\begin{array}{l}3-8 \text { months' feeding } \\
\text { interruption in } 981 \text { AWCs }\end{array}$ \\
300 days & None & & &
\end{tabular}

Source Compiled from various CAG reports.

Feeding interruptions at AWC level is a direct consequence of two important and interrelated governance issues in public service delivery procurement and financial management. There is no uniform procurement policy for ICDS commodities. In many states, government corporations are engaged to provide SNP without any competitive basis which is a reflection of poor procurement policy. Contract arrangements that include a number of sub-contracts are complex. Monitoring of contract performance is usually not well documented.

Then there is pilferage, wastage and lack of quality assurance in the supplementary nutrition programme. 'One of the reasons why the supplementary feeding does not reach the children is the fact that the entire feeding programme over the years has been passed into the hands of the private contractors who supplied ready to eat food powders that were culturally inappropriate, calorifically inadequate and in many cases, never reached the ICDS at all' (Saxena and Mander 2007). Media reports regularly mention the diversion of ICDS commodities into the open market. At times, rates fixed by government for rice and pulses are below the market rate. But audit reports found that purchases were made at uniform government rates, which raises doubts about quality, quantity and actual coverage of beneficiaries (CAG reports).

CAG is the Supreme Audit Institution of India, with branches in every state head quarters. It undertakes audits of government departments and public sector entities. Increasingly, because of the heavy workload, CAG audits of a particular department are bunched - covering
$3-5$ years in one go. This naturally creates delays and makes it difficult to respond to the findings. CAG report findings are taken up for discussion by the Public Accounts Committee to hold the executive to account. In general, CAG audits are considered of good quality, but because of the bunching of several years and the lack of strong follow-up from the PAG (because of delays and heavy workload), are considered largely ineffective in enforcing accountability.

The problem of finances starts with the budgeting process which is historically incremental and with an annual horizon and therefore limited flexibility. Then there is a major problem around the fund flows from the state to the front-line at the project levels. In many states, CDPOs report receiving funds late in the year. Due to weak accounting capacities within ICDS, statements of expenditure are not submitted on time which delays further instalments. In addition to the weak accounting, internal audit systems are weak or non-existent. Due to a combination of such factors, the financial system performs poorly and does not support the programme in general and procurement payments in particular.

Delays in payments to the suppliers is another major reason for the interruption in supplies. Due to non-streamlined financial management within the department, payments are delayed and suppliers run up huge bills. The suppliers then do not provide commodities until previous dues are cleared. As a result, feeding interruption takes place almost on a cyclical basis. CAG reviews mention these problems time and again. But responsiveness to the CAG observations is not very high. And because of 


\section{Box 2 Transportation problems beyond the interior areas}

Agents usually supply supplementary food commodity up to the block level and then it is left to the meagre resources of the anganwadi worker or disorganised private agents to transport the commodities to the AWC. In a situation where the distances of some villages from the block is $50-100 \mathrm{~km}$, this plays havoc with the supplies leading to feeding interruptions especially in the remote and far-off villages precisely where the supplementary nutrition is needed more.

many years of backlog of CAG reports, the Public Accounts Committee is not able to fix accountability for lapses (Box 2).

The recent cabinet decision to provide hot cooked meals across ICDS in the country can be used as a lever to provide new policy directions to the state governments on supplementary nutrition that takes into account value for money, timeliness in supplies and quality assurance and monitoring of performance. The financial system too needs strengthening to support the programme in general and procurement in particular.

\section{Nutrition and health education and gender}

ICDS has an important role in promoting nutrition and health education (NHE). NHE is a critical package of interventions containing information/counselling on a range of issues, such as: age of marriage/first child, importance of full immunisation, infant-feeding practices, complementary feeding, rest and care during pregnancy, which can all improve behaviours and positively impact on undernutrition.

Whether the NHE is followed well depends to a large extent on the awareness and status of women and their decision-making power in the family. Illiteracy among women and lack of exposure to media are emerging as important variables for malnutrition (Nair 2007). ${ }^{8}$ Studies confirm that women's status impacts significantly on child nutrition because women with higher status have better nutritional status themselves, are better cared for and provide higher quality care to their children (IFPRI 2003), and there is an inverse relationship between violence against women and the nutritional status of women. ${ }^{9}$

In general, ICDS and AWW priorities are managing food supplementation for children, rather than nutrition and health education. ${ }^{10}$ The
AWW has neither the time nor motivation to focus on NHE and on mothers' meetings due to their heavy workload. NHE is failing also because the AWW and ANM are not joining up effectively to provide critical behaviour change messages. The coordination with the health department is only effective in some cases. ${ }^{11}$ Many reports show that mothers do not feel motivated to attend the monthly meetings, and there is a large variation in the average attendance at the monthly meetings (20-60 per cent).

Interventions to encourage good caring behaviours are found to be cost-effective but require greater effort, support and capacity building of the anganwadi workers, which has not been a focus of the ICDS. ICDS IV with the focus on children under two years of age should devote resources to building the capacity of AWW for managing Behaviour Change Communication (BCG) and also should provide a second AWW to reduce workloads. While the first AWW can focus on early childhood education and work closely with the Education Department to develop such skills and capacity to deliver early education of the $3-6$ year olds, ${ }^{12}$ the second AWW could strengthen the health and nutrition linkages for the under twos and outreach socially excluded groups. Effective BCG can be delivered at scale, as demonstrated by CARE India's Integrated Nutrition and Health Project II (INHP II) evaluation which highlighted the gains from targeting behaviour change interventions at the youngest children (under twos) and pregnant women, with the greatest impact on exclusive breast-feeding and neonatal care practices (CARE 2008).

\section{Planning and monitoring}

Monitoring is one of the weak links in ICDS. In Bihar, the CAG 2007 reports that basic statistical information, such as birth weight, maternal mortality rate, infant mortality rate, institutional delivery and enrolment of children 
Box 3 Inclusive monitoring and planning (UNICEF/KPMG 2008)

In one of UNICEF's supported districts in Jharkhand, with support from district administration, weighing efficiency of children increased from 38 per cent to 75 per cent, based on better monitoring. This monitoring is supported with simple monitoring tools, and building the capacity of the AWW and community to use it effectively.

UNICEF has supported the positive deviance model in Orissa, where the AWW and the community monitor the weight of the children, the deviance from the normal growth, learn how others manage to have normal weight babies and support effective action to improve the weight of the underweight children. This proves that inclusive monitoring and planning can help to significantly improve performance.

in regular schools after pre-school education for planning, was unavailable with the Directorate in Bihar (CAG 2007). No growth chart was found in any of the test-checked AWCs in Bihar.

In MP, it was noted that the data in the Monthly Progress Report (MPR) was not reviewed at any level. For instance, infant mortality was reported as almost nil in the MPRs while infant mortality rate (IMR) in the districts (Damoh, Mandla and Vidisha) was 75.8-96 per 1,000 live births during 2004-05 (CAG Performance Review 2005-06).

Orissa reviews by CAG noted that the monitoring of progress in ICDS was poor. The committees at the state and district levels did not record and analyse progress properly. It was found that visits by CDPO Supervisors to the AWCs were inadequate and some AWCs were never visited by CDPOs in a span of three years. At the AWC level, except for immunisation data and information on SNP, other data related to NHE growth charts were very poor.

Where AWWs have been supported to monitor the growth better, the weighting efficiency has improved leading to better monitoring and effective action for underweight children to gain weight (Box 3). ICDS IV pays special attention to this area which is encouraging.

Overall, there is little focus on putting the beneficiary at the centre of service delivery through ICDS in terms of planning and monitoring. No clear transparency standards are followed and actively disseminated to ensure beneficiaries are aware of entitlements and service quality. As a result, most communities especially those belonging to marginalised groups, do not have a clear idea about the multiple objectives of ICDS. A majority of perceptions equate ICDS with the provision of supplementary nutrition only. This not only damages the accountability relationship between the ICDS and the communities but also fails to create a compact between the serving institution and the community.

\subsection{Responsiveness}

The Right-to-Food (RTF) Campaign spearheaded by the People's Union for Civil Liberties (PUCL) in India, which is a broad coalition of civil society, activists and academics, has succeeded in placing hunger at the centre of development discourse in India. The campaign has successfully advocated through the legal route to get the Supreme Court to direct the Indian government to improve the functioning of ICDS by adopting specific measures. On 28 November 2001, the Supreme Court first directed the central and state governments to ensure that there is a functional anganwadi 'in every settlement'.

The Supreme Court orders (Box 4) have focused on addressing the equity issue by directing the government to sanction more AWCs starting with ST/SC habitations and urban slums and move towards universalisation. It also introduced the concept of AWC on demand. ${ }^{13}$ In line with the approach of covering the last mile, the GoI has been directed to operationalise 1.4 million AWCs by December 2008, and GoI has sanctioned 1.05 million AWCs and most of the poor states have operationalised up to 95 per cent of the sanctioned AWC. The GoI and state governments have made tremendous efforts to respond to the directives of the Supreme Court.

However, responding to the need for improved quality of services provided by ICDS especially 
The secretariat which supports the Supreme Court appointed Commissioners has carried out significant analytical work on ICDS in the last few years. As a result of this institutionalised and persistent advocacy, significant impact has been achieved. This is a special case as the legal route has been adopted while other advocacy efforts have not been as effective.

Attributable to the advocacy campaign are the following changes: (1) increase in the number of operational AWCs, especially in the underserved areas (going up from 600,000 AWCs in 2004 to 1.4 million in 2008); (2) universal eligibility for supplementary nutrition instead of the Below Poverty Line (BPL) list; (3) quadrupling of budgets for every child in the ICDS between 2004 and 2008 and (4) a recent clear cut policy decision to provide hot cooked meals in all ICDS projects.

for the socially excluded groups is more challenging. It is one thing to 'open a centre' in the SC/ST habitations and it is quite another to improve services there. Ramchandran ${ }^{14}$ (2005) and Mander and Kumaran (2006) have found evidence of social discrimination based on caste, where the majority of the AWW were from a higher caste (70-4 per cent) and they did not provide adequate coverage to the low caste or tribal hamlets or ignored them.

Quality improvements will require a combination of governance changes such as more representative staff from these lower castes, better operational support to the AWW to be responsive to the needs of those residing in remote hamlets, better nutritional supplies and effective monitoring to track the excluded groups, etc.

There are several demand side constraints too; from indifference in the society towards the marginalised groups to active discrimination against them. Attendance by children of a particular caste appears to be influenced by the caste of the anganwadi worker (World Bank 2005) and also the venue of the AWC (if a religious place or the houses of higher caste AWW, those from lower castes are less likely to attend) (Box 5).

Responsiveness to tackling social exclusion is central to improving food and nutritional security. In most places, the families that were excluded from ICDS due to social discrimination or poverty also tended to be excluded from other food schemes. This exposes them to long periods of uncertainties and denials (UNICEF/KPMG 2008).

Overall, it is found that 36 per cent of the poor had no coverage under any food security schemes as more than one-third of them did not have any Below Poverty List (BPL) or Antodaya Card, and this was worse for poor states like MP and Orissa (42 per cent and 54 per cent of the poor did not have these cards, respectively). ${ }^{15}$ Policy responsiveness to such discrimination does not seem to be very high on the agenda though the RTF is making a difference.

Ultimately, institutional design for responsiveness must strengthen local level accountability. Panchayats could play an effective role in holding the health and nutrition workers

\section{Box 5 Active social discrimination}

Mandar and Kumaran (2006) studied social exclusion in ICDS in four States - Andhra Pradesh, Chhattisgarh, Jharkhand and Uttar Pradesh. They found that a large number of eligible children from impoverished and food-deprived households could not access ICDS. The denial of these services is not random or accidental but is frequently the outcome of active social discrimination based on caste, gender and disability. They did not find any centre located in adivasi/dalit hamlets and there were subtle forms of discrimination by the anganwadi worker service providers, e.g. missing out the homes of adivasis/dalits during the rounds made to collect children to come to the centre (UNICEF/KPMG 2008). 
accountable. ${ }^{16}$ NGOs like MV Foundation have piloted models to build the capacity of the Panchayats and Self-Help Groups (SHGs) to hold ANM and AWW workers accountable for services on the Fixed Health and Nutrition Days.

However, greater oversight of state level groups, networks and organisations of the socially excluded and marginalised are also needed to ensure that local institutions actively respond to the needs of the socially excluded. The United Nation agencies and international NGOs could support socially excluded groups to advocate for appropriate models to support the government to reduce child malnutrition in these communities. The National Commission for the Protection of Child Rights is playing an important role in setting the framework for child rights. Through its network of civil society organisations (CSOs) and other networks, and with effective use of media, it can create an impetus to break the apathy of the general public to this crisis, to expand the basic rights of the child to include education and freedom from hunger.

\section{Conclusions and recommendations}

It is easy to conclude that governance as usual will not work to improve the nutritional outcomes for 75 million undernourished children in India. We arrive at three main sets of conclusions and recommendations.

The first main conclusion is that child undernutrition is not a high political priority in India. This however is changing and the government is showing urgency in tackling the issue. Since tackling undernutrition is still not a strong political priority, one of the major challenges is to advocate for positioning child undernutrition at the top of the government's policy priorities. This will happen when advocacy efforts are well joined up between civil society groups and international agencies, building on the guidelines of the Supreme Court and the RTF campaign. The PM's National Council, the Planning Commission with support from WCD should prepare a time-bound medium term (2-3 years) National Action Plan on tackling child nutrition that requires all relevant sectors to respond as a whole. This will have a knock-on effect at the state and district levels and should lead to more cross-government action on tackling child undernutrition. An annual action-taken report may be tabled in Parliament by the government - which can be scrutinised by the various interest groups and the media. Such an institutional process will ensure continuous high level focus on child undernutrition.

The second important conclusion is that ICDS in its current design is not successful because it neglects crucial governance issues such as personnel management, procurement, financial management and planning and monitoring for results. Also there is a weak focus in ICDS on reaching out to excluded groups. As a result, poor people, especially those belonging to marginalised and socially excluded groups cannot effectively claim their rightful entitlements. A number of programme delivery parameters need to change and governance issues must be paid more attention to in ICDS. The AWC infrastructure is crumbling and particular attention must be given to develop new AWCs as per the norms with particular focus on provisioning of drinking water and toilets. Social audits must be undertaken to ensure norms are adhered to. High levels of vacancies at the CDPO and supervisory levels are damaging the programme and must be reduced as a matter of urgency. An overarching personnel policy must be drawn up, made transparent and enforced diligently to ensure remote and underserved posts do not remain vacant for a long time. Steps for better supervision and management support should be also taken up.

Procurement and financial systems for supplementary nutrition is not working, leading to significant feeding interruptions. What is needed is a transparent and effective procurement policy that ensures value for money, timeliness in supplies, quality assurance and monitoring of performance. The latest Cabinet decision to provide hot cooked meals should provide that impetus. Financial management systems should be overhauled, including improved budgeting, accounting and audits. Internal audits must be strengthened to improve accounting and financial systems.

Responsiveness to external audits must be improved so that observations made by $\mathrm{CAG}$ reports are taken up effectively. The PAC must be supported more strongly to enforce democratic accountability.

Planning and monitoring systems in the ICDS should be overhauled with a focus on stronger 
independent assessments, including beneficiary feedback. Voices of socially excluded groups through independent studies should complement the existing monitoring and evaluation system. These findings need to be published to keep up the pressure for better performance. There must be stronger accountability of ICDS district level officers who need to be anchors of the monitoring system. Currently, there is not enough scrutiny of the system and therefore, quality is poor. GoI too must play a stronger role in quality-checking the MIS of ICDS and in evaluating outcomes and impacts.

The final conclusion is that the Indian state is becoming increasingly responsive to the rights and entitlements of marginalised groups because of internal policy changes, and also in response to the pressure from advocacy groups mediated through the Supreme Court. This needs to

\section{Notes}

* The views expressed in this article are the authors' and do not necessarily represent the views of DFID or of the organisation in which they work.

1 Provides a package of six services: supplementary nutrition, non-formal, preschool education, nutrition and health education, immunisation, health check up and referral services and nutrition. The last three services are delivered in convergence with the health department.

2 Montek S. Ahluwalia, Deputy Chairman, Planning Commission of India makes a point '... somebody says child malnutrition is a disgrace and it's actually true, and then they say well, we have this programme to take care of child malnutrition, so let's quadruple the money we are spending on it. And the answer is that that may not actually be what you need to do. Just because a programme has child malnutrition in its title doesn't actually mean that it's relating to the critical interventions'.

3 The six large states are: Madhya Pradesh, Bihar, Gujarat, Uttar Pradesh, Orissa and Rajasthan and the two tribal states of Jharkhand, Chattisgarh.

4 Some 47 per cent of adolescent girls aged 15-19 are undernourished, which reduces to 38 per cent for ages 20-29, NFHS-3.

5 Under this programme, children up to six years old should be provided with 300 calories and $8-10 \mathrm{~g}$ of protein; adolescent girls, 500 continue with better collaborative mechanisms between the state and civil society actors. In addition, some specific steps may be taken for enhancing responsiveness through the ICDS. They are: (1) selection of appropriate AWWs from the local community and from SC/ST background with appropriate training and support; (2) sensitisation of all AWWs supervisors and CDPOs on social exclusion issues; (3) dispersal of AWC/sub-centres to tribal or caste hamlets; (4) capacity building and sensitisation of supervisory cadres to track reach of services for excluded social groups; (5) provision of second AWW to focus on children under two years of age; (6) improved capacity for delivering higher quality of nutrition and health education, including counselling on feeding practices, information on balanced nutrition for women and on violence against women.

calories and 20-25 g of protein per day and pregnant and nursing mothers, 500 calories and $20-25 \mathrm{~g}$ of protein per day.

Undernourished children are entitled to double the daily supplement provided compared to the other children (600 calories and/or special nutrients on medical recommendation). It is a centrally sponsored scheme with 100 per cent financial assistance from GoI, except for 50 per cent of supplementary nutrition, which is borne by the state governments.

6 Norm - One Anganwadi centre should cover 1,000 general population and 700 tribal population.

7 Covering 287,684 AWGs.

8 Malnourishment among children in India: a regional analysis.

9 Latest research by S.V. Subramanian found that one instance of domestic violence in the previous year increased the likelihood of being underweight by 21 per cent, as the sphere of decision-making is affected, and associated with higher levels of stress (Ackerson and Subramanian 2008).

10 Overall pregnant and lactating women's use of AWG is very limited (22 per cent and 17 per cent, respectively) and the main focus is on supplementary food and very limited for health and nutrition counselling (coverage of 11 and 8 per cent, respectively).

11 West Bengal's strategy of regular 4th Saturday meetings, whereby ICDS and Health 
functionaries jointly assess their programmes with the local gram panchayats seems to be delivering results.

12 Tamil Nadu has developed good models for early childhood education.

13 The Supreme Court in its order dated 13 December 2006 directed that rural communities and slum dwellers should be entitled to an 'Anganwadi on demand' (not later than three months) from the date of demand in cases where a settlement has at least 40 children under six but no Anganwadi.

\section{References}

Ackerson, M.L.K. and Subramanian, S.V. (2008) 'Domestic Violence and Chronic Malnutrition among Women and Children in India', American Journal of Epidemiology 167.10, http://aje.oxfordjournal.org/cgi/contentfull/ kwn049 (accessed 30 April 2009)

Adiga, Aravind (2008) The White Tiger, London: Atlantic Books

CARE (2008) Women and Child Health at Scale, Rachna Programme, Working Papers Series, New Dehi, GARE

Census of India (2001) 'State Wise Population Totals', CyberJournalist, India, http://cyberjournalist.org.in/census/ cenindia.html (accessed 16 May 2009)

Comptroller and Auditor General (CAG) (2005-07) Civil Audit Reports (ICDS Performance Reviews) (Bihar 2007, Madhya Pradesh 2005, Orissa 2006 and W. Bengal 2005), www.cag.gov.in (accessed 16 May 2009)

DFID (2008) Three Faces of India: DFID India Country Plan 2008-2015, London: Department for International Development, www.dfid.gov.uk/pubs/files/india-cap.pdf (accessed 30 April 2009)

DFID (2008) How-to Note: Country Governance Analysis, DFID Practice Paper, www.dfid.gov.uk/pubs/files/how-to-cga.pdf (accessed 30 April 2009)

DFID (2007) Governance, Development and Democratic Politics: DFID's Work in Building More Effective States. London: Department for International Development, www.dfid.gov.uk/ pubs/files/governance.pdf (accessed 30 April 2009)

GoI Government of India (2007a) Annual Report, Ministry of Women and Child Development

GoI Government of India (2007b) 'Governance', chapter in Eleventh Five-Year Plan
14 Two districts of UP over 70 per cent of AWW were from higher caste or OBCs; in AP 74 per cent of AWW sampled were from nonscheduled groups.

15 Poor beneficiaries under four food schemes ICDS, Food for Work (FFW), Annapurna, Mid Day Meal (MDM), according to NSS 2004-05.

16 In Kerala, Panchayats have played a major role in overview and accountability of the ICDS programme.

GoI Government of India (2007c) ICDS-IV Project Handbook, Government of India: Central Project Management Unit, Ministry of Women and Child Development, 31 December, http://motherchildnutrition.org/ india/pdf/mcn-icds4-handbook.pdf (accessed 16 May 2009)

GoI Government of India (2007d) 'Nutrition and Social Safety Net', chapter in Eleventh Five-Year Plan

GoI Government of India (2007e) Project Concept Note (Revised), Government of India: Central Project Management Unit, Ministry of Women and Child Development, 14 September

IFPRI (2003) Newesletter, www.ifpri.org/pubs/ abstract/131/ab131.pdf (accessed 16 May 2009)

International Institute for Population Sciences and ORC Macro (2000) National Family Health Survey (NFHS-2), 1998-99: India, Mumbai: IIPS

International Institute for Population Sciences and ORC Macro (2007) National Family Health Survey (NFHS-3), 2005-06: India 1, Mumbai: IIPS

Mander, Harsh and Kumaran, M. (2006) 'Social Exclusion in ICDS: A Sociological Whodunit?', unpublished

Nair, K.R.G. (2007) 'Malnourishment Among Children in India: A Regional Analysis', Economic and Political Weekly, 15 September

Ramachandran, Vimala (2005) 'Reflections on the ICDS Programme', Reclaiming Childhood: a Symposium on Early Childhood Care and Education, www.india-seminar.com/2005/546/ 546\%20vimla\%20ramachandran.htm (accessed 16 May 2009)

Saxena, N.C. and Mander, Harsh (2007) Report on ICDS in the Case PUCL v. Union of India, 30 August, New Delhi: Office of the Commissioners of the Supreme Court (CWP 196/ 2001), www.sccommissioners.org/ 
pdfs/comreports/icdsreportaugust2007.pdf (accessed 16 May 2009)

Saxena, N.C. and Ravi, J. (2005) Governance Issues in ICDS, http://pmindia.gov.in/nac/ concept $\% 20$ papers/icds.pdf (accessed 16 May 2009)

UNICEF/KPMG (2008) Formative Evaluation of Integrated District Approach

UNICEF India (2009) Interpretation of 'District Level Health Survey Reports, and other presentations

Working Group on Children Under Six (2007) Economic and Political Weekly, 29 December, http://unicef.globalstudy.googlepages.com/ EPWARTICLEStrategiesforChildrenunder.pdf (accessed 16 May 2009)
World Bank (2009) Revised Poverty Estimates: What does this mean for India?, Washington DC: World Bank, www.worldbank.org.in/WBSITE/ EXTERNAL/COUNTRIES/SOUTHASIAEXT/ INDIAEXTN/0,contentMDK:21880804 pagePK:141137 piPK:141127 theSitePK:29 5584,00.html (accessed 30 April 2009)

World Bank (2005) India's Undernourished Children: A Call for Reform and Action, August, Washington DC: World Bank

World Bank (1991) Managing Development - The Governance Dimension, Washington DC: World Bank, www-wds.worldbank.org/external/ default/WDSContentServer/WDSP/IB/2006/ 03/07/000090341_20060307104630/Rendered/ PDF/34899.pdf (accessed 30 April 2009) 